\title{
Does Archaeology Stink? Detecting Smell in the Past Using Headspace Sampling Techniques
}

\section{Rose Malik ${ }^{1}$}

Published online: 21 July 2020

(C) The Author(s) 2020

\begin{abstract}
Smell is a language, communicative and interpretive. Firmly embedded in the physical, social, emotional, and semantic context, odor emanates as existential expression that is integral and idiosyncratic to human culture, behaviors, and practices. Advances in scientific techniques allows for odor to be used as primary source evidence. Focusing on a ground-breaking technique, headspace sampling provides direct access to ancient odor molecules for analysis. This paper explores how empirical information permits entry into previously unexplored sensorial sociocultural avenues that enable deeper, richer models of archaeological interpretation.
\end{abstract}

Keywords Odor $\cdot$ Smell $\cdot$ Odor molecules $\cdot$ Headspace sampling $\cdot$ Bioarchaeology

\section{Introduction}

Headspace sampling is an innovative technique that allows direct access to ancient odor molecules for analysis. This method used in conjunction with gas chromatography and mass spectrometry (GC-MS) processing detects and identifies odor analytes.

The aims of this research are to explore how archaeology can engage with ancient smells and to demonstrate how headspace sampling can evolve the way odor is considered as primary source evidence in archaeology. Another issue to explore is how headspace sampling methodology may enable multi-faceted engagement that bridges the gap between science and archaeology.

Field archaeology has often only been willing to access material culture that is visible and tangible in essence (Day 2013: 1-5). The invisible has remained uncaptured and unchallenged. Questions about finding smell in the field have been raised but often dismissed (Bartosiewicz 2003; Day 2013: 5). While much archaeological focus has

Rose Malik

rose.malik@durham.ac.uk

1 Durham University, Durham, UK 
been on the practicalities of excavation, some archaeologists have been considering ways of finding smell in the field and are recognizing smell as an important source material.

Developments in odor analysis in the 1990s emerged with Buck and Axel's (1991) identification of olfactory receptors in rats. Since 2000, empirical analysis into odorous biomolecules in ancient preservation has built considerable momentum (Buckley and Evershed 2001; Buckley et al. 2004, 2007; Dong et al. 2009; Niimura and Nei 2003, 2005). In fact, a headspace sampling technique has been employed to analyze archaeological material. For example, a study of the prehistoric origins of Egyptian mummification in the late Neolithic burials (Jones et al. 2014: 1-13) demonstrates the great potential headspace sampling offers to access "ancient" odor in archaeology. Indeed, Bembibre and Strlič (2017) use headspace analysis to discuss odor and assess how smells can enhance our present-day heritage experiences of past odor. However, few studies have used this method to analyze ancient materials or to explore the lived experiential nature of the original odor emanations of past peoples.

In addition, field archaeology has been slow to move from the conceptual theory toward using science-based methods to find olfaction within the ancient material record. It has been biogenetics and neuroscience, more often than not, that have made empirical inroads into olfactory research (Reinarz 2014: 212-213). For example, by examining early hominid cognitive development and subsequent behaviors (Dong et al. 2009; Hoover et al. 2015; Niimura and Nei 2003, 2005, 2014).

In archaeology (both field and sensory), using empirical data from headspace sampling analysis and conceptually based interpretations allow routes into sensorially based sociocultural narratives. The combination of empirical data and archaeological theory gives scope for developing more robust interpretations and presenting another more experiential dimension to archaeological explorations - making the incorporeal odor molecule a tangible, visible, primary source.

\section{Odor Exploration in Archaeology}

Analysis, as yet, has not for the most part established the same level of archaeological olfactory-focused interpretations in the same way as conceptual approaches. Encouragingly, a new era for olfactory archaeology is looming on the horizon. Biogenetics has paved the way for smell to emanate as a tangible presence in archaeology by combining empirical - science-driven - data with conceptual - archaeological interpretive narratives (Cano 1996: 162-167).

Although smell theory opens pathways into archaeological discourse, finding empirical evidence has seemed more accessible through the experiential but only observed as a side issue of experimental archaeology or anthropological studies, such as for exploring technological Iberian plaque making (Thomas 2013: 335-348).

Consequently, smell has only been considered as a singularity and a form of enculturation (Reinarz 2014: 1; Skeates 2010), rather than a sensory factor of a priori cognitive adaptation and functionality. Susan Harvey's (2006) Scenting Salvation evaluates scent as historically having socioculturally ontological significance. Whereas Chris Woolgar's (2006) The Senses in Late Medieval England reviews the prominence of sensory experience in Christian literature and its implications as an epistemological 
and pedagogical tool. On the other hand, Constance Classen, David Howes, and Anthony Synnott in Worlds of Senses (1993), Aroma (1994), and The Colour of Angels (1998) introduced social science and anthropological approaches to the olfactory agenda. Thus, presenting a systematic "mapping" of the role of scent as a sociocultural phenomenon (Classen 1993, 1994, 2014; Harvey 2006; Reinarz 2014: 2-9, 212; Woolgar 2006).

Clearly much of the literature about smell lends itself well to disciplines that readily conceptualize and theorize, and do not necessarily require empirical evidence upon which to base assumptions (Reinarz 2014: 2-9, 177-208, 209-218). Indeed, most discussions around smell seem to have been anchored in the more ephemeral aspects of historical or sociological understanding; of what the smell profile might imply, including Reinarz's (2014) own exposition of the history of smell. However, could these studies be made more robust by providing empirical evidence from deconstructing odorants?

Sensory studies in archaeology have focused on four of the primary senses to provide primary source evidence in examining social constructs particularly in periods concentrating on early human evolution (Fig. 1). Approaches have given far more attention to the "tangible" senses such as taste (Hardy et al. 2012; Saul et al. 2013), touch (Pettitt et al. 2014; Rifkin 2009; Tringham 2013), sound (d'Errico et al. 2003; Morley 2002, 2006), and vision (Hodgson 2008). Although smell has been addressed, it has remained mainly conceptual or theoretical (Day 2013; Pawlowska 2014). Smell is one of the sense criteria for informing early human evolutionary engagement, but neither olfactory associations nor any clear connections presented between cognition, olfaction, and adaptation are directly discussed.

The literature from 2000 onward reflects a shift toward a more factual and empirical base in considering odor. Later theories evolving out of phenomenology such as

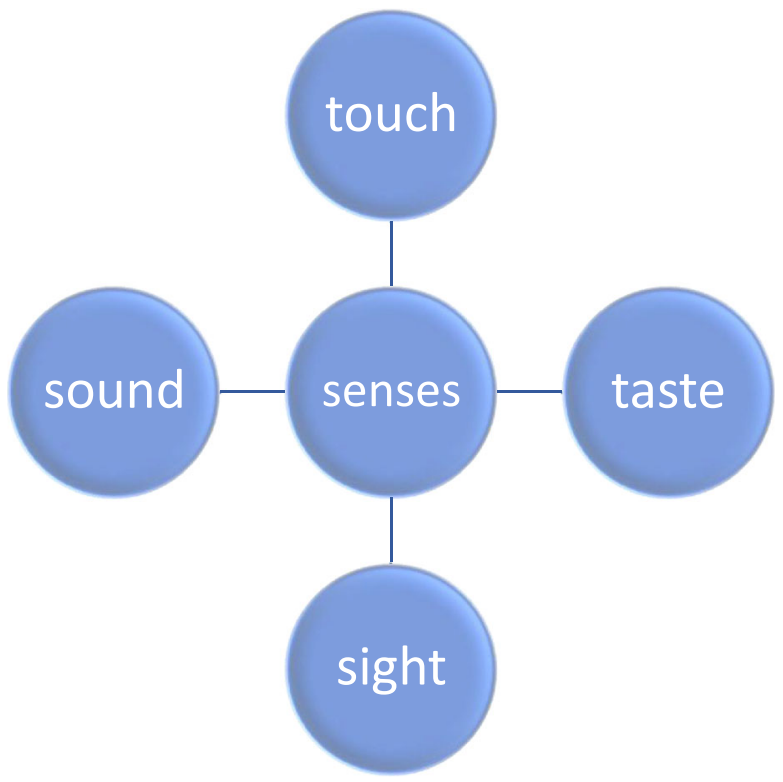

Fig. 1 Senses considered as tangible primary source evidence in archaeology 
entanglement theory can be seen to include olfaction to explore sensory networking and cognitive adaptation (Fig. 2) (Hodder 2016; Skeates 2010).

Odor has a great impact on our conceptions of agency, meaning, and person. Smell signatures tie into material embodiment and cognitive action through meaning and placement (Fig. 3); meaning and interpretation; meaning and engagement (Franklin and Ferkin 2006: 36-40; Malafouris 2004, 2017).

Olfaction enables a new approach to the embodied and environmentally situated character of being human and can be evidenced through empirical data (using new scientific approaches) to support the broader conceptual archaeological interpretations and narratives.

Multidisciplinary approaches have incorporated science and archaeological research, particularly as a subdivision of the discipline; bioarchaeology, for example, recognizes that past genetics and cognition can bring salient information to understanding human behavior.

Thanks to developments in aDNA analysis (Cano 1996; Nicholls 2005), empirical data has made headway enabling a wider scope into sensory studies. For example, Saul et al. (2013) test the phytoliths preserved in carbonized food deposits in prehistoric pottery and aromatic spices used in European prehistoric cuisine to discuss taste in the western Baltic dating from 6,100 cal BP to 5,750 cal BP.

Hardy et al. $(2012,2013,2018)$ use empirical evidence to discuss the concept of medicinal use among the Neanderthals. Dental calculus analysis revealed evidence to suggest that Neanderthals digested bitter plants not for the taste but potentially for medicinal purposes (Hardy 2018: 393-405; Hardy et al. 2012: 617-626, 2013: 873-878).

Nevertheless, there is little mention of the odorous implications in these studies. Brettell (2014), on the other hand, does show that analysis can be brought to bear on archaeological interpretations of smell and its importance within a thematic narrative, such as Roman burial practices in Britain (Brettell et al. 2014: 444-459, 2016) and organic residues in Egyptian votive mummies (Brettell et al. 2017: 68-82).

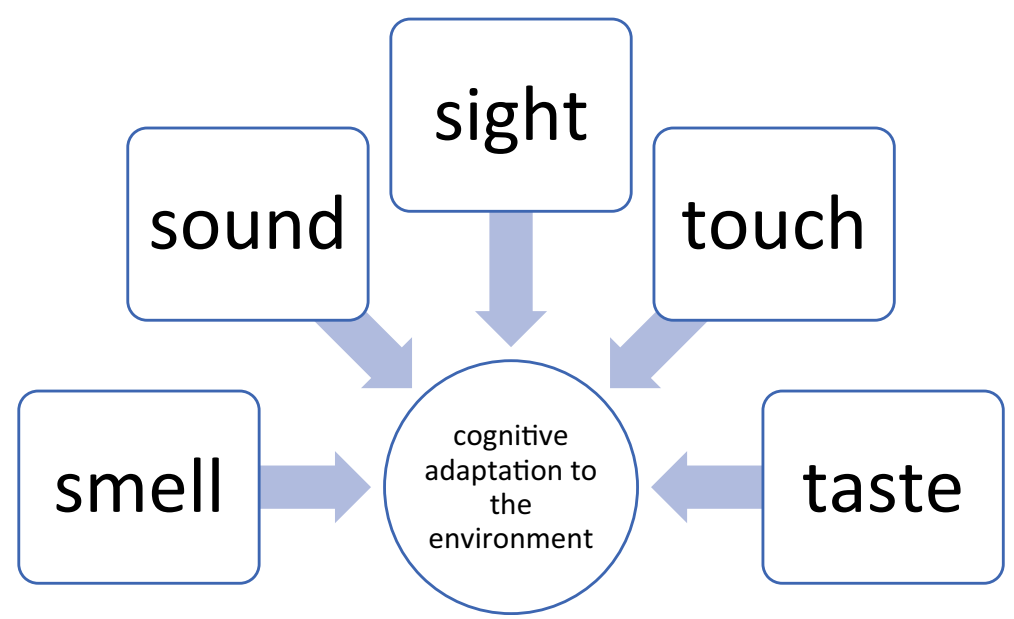

Fig. 2 Epistemic model of interconnection of the senses impacting on cognitive interpretation and adaptation to the environment 


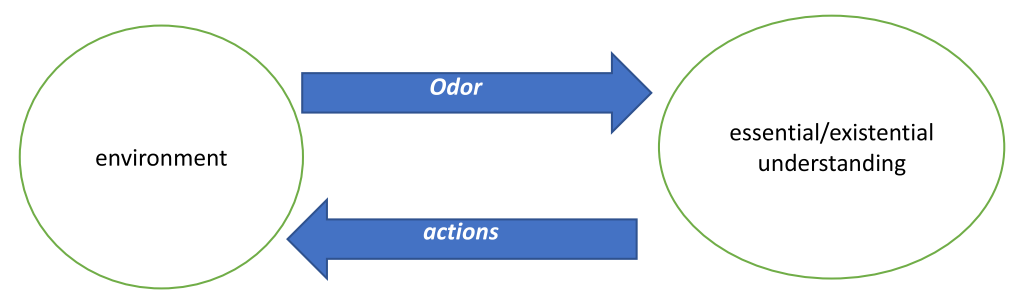

Fig. 3 Epistemic model of movement between olfaction from environment and cognitive interpretation and adaptation to that environment

In conjunction with this, scientific descriptions of the mnemonical nature of smell have given more credence to the connection between chemical compounds, the olfactory system, and the brain. This has led to more recent investigations in biogenetics and neuroscience which discuss olfaction as essential for the survival of animals, including humans (Niimura 2009: 107). Thus, smell has begun to take its primary place in research on the senses. However, although recognized as integral to human evolution, biogenetics has been inclined to keep much of its research more about the genetic composition around human olfaction. Discourse, particularly focused in early prehistoric periods (where little material culture may survive), has involved insights into how volatile odor molecules in the environment are received by olfactory receptors (Niimura 2009: 106-8).

It is clear, then, that there is scope for the use of olfactory data to further develop archaeological interpretations of past cultural constructs, practices, and behaviors.

\section{How is Odor Important in Understanding Human Behavior?}

Olfaction has a significant role to play on human cognition and adaptation to our environments. Smell feeds into the part of the brain, known as the limbic system (Fig. 4), which controls our long-term memory, emotions, and learning capabilities (Engen 1982: 18-29; 97-110; Hamilakis 2002, 2010; Heyes 2012).

As part of the sensory collective and as an individual sense, smell effectively enables material engagement and ontological development (Fig. 5). The limbic system controls our cognitive understanding: existential, conscious decision making, and behavioral patterns.

Odor biomolecules, seemingly short lived, penetrate and subsequently linger as mnemonically driven encoded messaging to become entrenched in long-term memory, long after the detectable odor (by nasal detection) has passed. Odor molecules penetrate the brain via the olfactory bulb (Fig. 6), where the molecules are trapped in the cilia, activating the olfactory receptor cells which in turn send electrical signals to the limbic area. It is there that these signals inform cognitive responses: how we think, behave, and conceptualize the world around us. This makes odor an interesting aspect of innate human nature.

Questions abound around how the odor molecules connected with the cilia in the nasal epithelium remain long enough to make an impression on the limbic system. A theory put forward in the 1930s was a vibration theory suggesting that odor molecules vibrated and created the signals in the cilia (Hoehn et al. 2018). Amoore's (1952) shape theory defined volatile odor molecules as having shape which worked on a lock and 


\section{The Limbic System}

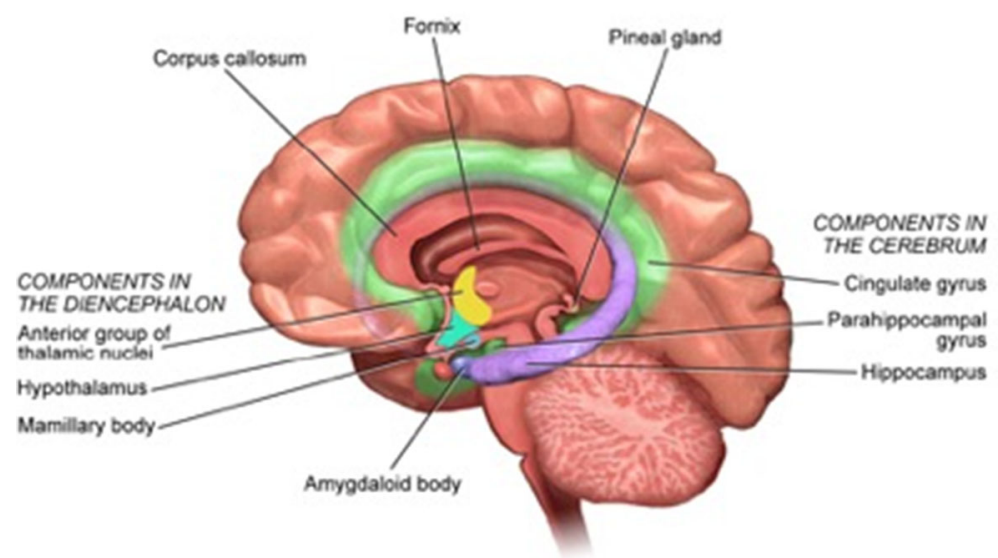

Fig. 4 The limbic system https://en.wikipedia.org/wiki/Limbic_system\#/media/File:Blausen_0614_ LimbicSystem.png

key system; the molecule locking into the cilia generating responses in the olfactory receptors (see Fig. 6), triggering and sending electronic signals to the limbic area (Amoore 1971; Engen 1982: 17-34). Turin (1996) combined vibration theory with the lock and key theory, suggesting that an electronic tunneling system by which the vibrational molecules effectively "burrowed" their way through to the cilia where they interlocked in the right place for sending signals to the limbic system (also see Hoehn et al. 2018).

As discussed above, Buck and Axel (1991) first discovered olfactory receptors (ORs) in rats, which opened the door to subsequent olfactory research (Niimura and Nei 2003, 2005). Studies escalated into the identification of the entire repertories of OR genes using bioinformatic methods from the whole-genome sequences of diverse

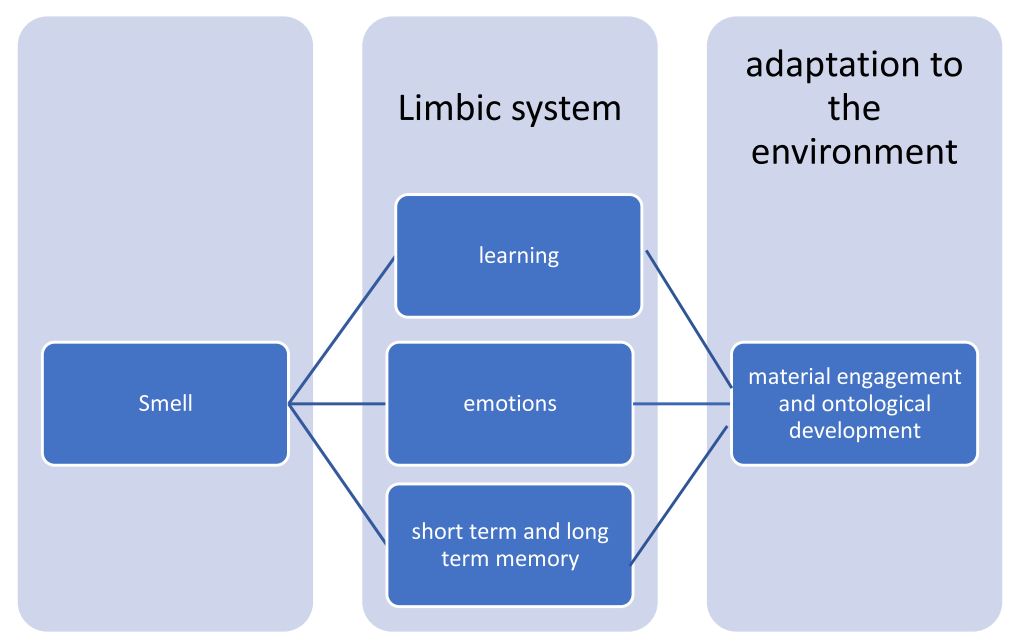

Fig. 5 How smell affects the limbic system which in turn affects human understanding and adaptation to the environment 


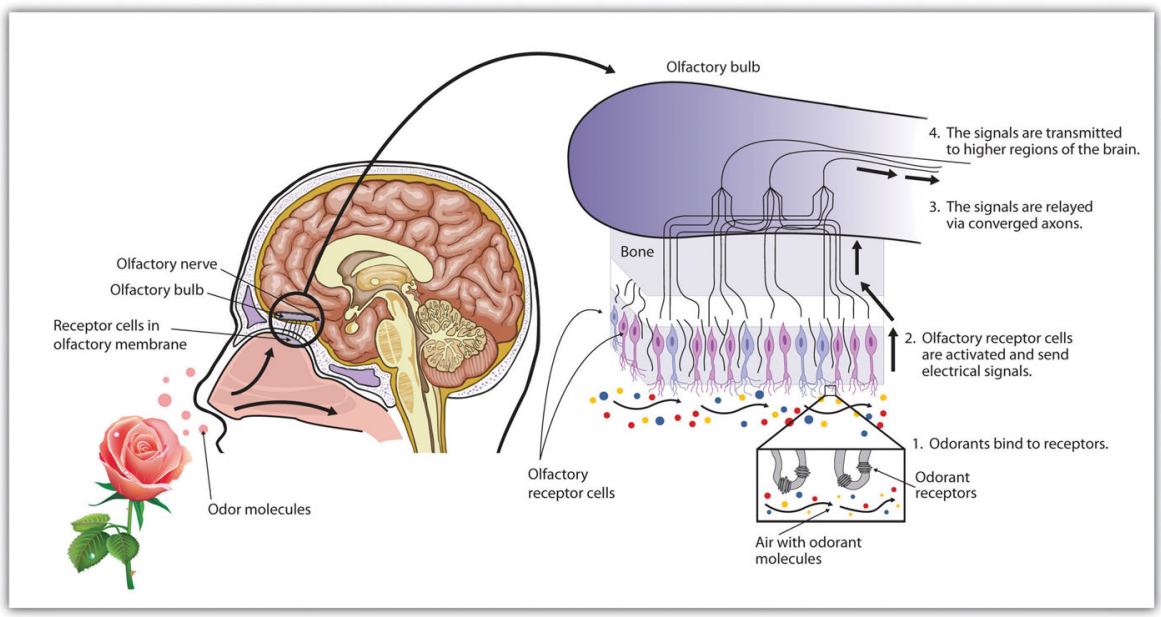

Fig. 6 How the olfactory system works https://opentextbc.ca/introductiontopsychology/wpcontent/uploads/sites/9/2013/11/8160ad1108b8ba82ab80260f3e7b5161.jpg licensed by creative communications.org: https://creativecommons.org/licenses/by/4.0/

organisms which revealed that the numbers of OR genes vary enormously in different species, ranging from 1,200 in rats (Niimura 2009: 107) to just 400 in humans. Although this number may seem small in comparison, human ORs can detect up to 10,000 odors and the nasal passage can be affected by a trillion odorant stimulants (Bushdid et al. 2014; Dong et al. 2009: 261).

These studies show that it is possible to use empirical data from odor biomarkers to build an olfactory epistemology that allows access, analysis, and subsequent data-led interpretation into human cognitive behavior. It follows then that archaeology could use this same data to analyze ancient sociocultural existential expression; symbolic cultic, deviant, or ritualized practices; and to fortify or re-examine our understanding of landscapes and spatial environmental adaptations. For example, there is scope to examine the olfactory biomolecules present in psychoactive substances used in ancient shamanic rituals (Miller et al. 2019) to discuss the metaphysical and experiential impact of smell to the shamanic performance.

In addition, the nature of odor exudation related to essential processes and ritualistic behavior associated with burial can be explored. The anti-bacterial, medicinal, or insecticidal properties can be contrasted with the experience of smelling aromatic substances during use. This provides opportunity for archaeological interpretations of the wider existential meanings around the act of burial. For example, the chemical structure of cinnamon indicates preservative properties, and in use emits a sweet uplifting note. This odor, as experienced during the preparation of the body for burial, may become associated with the smell of preservation of the soul and, consequently, held in high or sacred esteem as a substance for treating the body in readiness for the afterlife. As this symbolic expression is continually ritualized, its association with the smell of sanctity grows more complex.

Thus, odor facilitates conscious (and subconscious) symbolic storage (Engen 1982: 102-110), which can inform deeper interpretations of past performative behaviors (Halbwachs 1950: 47, 52; Jones 2007: 42-44, 61-69). 
In archaeology, then, the fundamental question is whether we can extract an "olfactory molecule" from ancient material culture, and if so, how. Former studies have shown this is possible (Brettell et al. 2014, 2016; Hamm et al. 2005: 1499-1519), but the strategies and protocols of finding smell in the field have not yet been fully explored. Thus, by developing a critically aware methodology and technique to extract dormant odor molecules, we could access olfaction as a primary source to bolster or recreate our archaeological narratives.

\section{Methodology of a Smell Technique}

The headspace with gas chromatography-mass spectrometry (GC-MS) technique has proved to be a powerful analytical tool in other industries and disciplines for the last 40 years (Tipler 2014: 3-5, 33). This technique may offer opportunities for greater understanding of the archaeological record.

Headspace sampling methods, used in the field, negate the physical appliance of the nose - it goes beyond simply "sniffing up" the past, rather it provides a means to find irrefutable empirical odor evidence. In essence, the archaeology of smells can be studied directly from site to laboratory, bringing scientific analysis to past olfaction. Bartosiewicz (2003: 175-195) has raised concerns of environmental conditions and exposure affecting the analytical information collected. However, a systematic methodology for odor extraction, which takes account of the particulate matter from an excavation, could mean that the olfactory data would prove useful in understanding the effects of the environment on olfaction in material remains.

As a "tangible" primary source of evidence, the extrapolated data can be used to more fully reconstruct past lived experiences. Whereby, this methodology can produce datasets for analysis that reveal the application of particular aromatic agents to discuss the broader narratives, around for example, the "essential" ritualized mortuary practice in conjunction with the "existential" cognitive processes that manifest as symbolic meaning within the wider sociocultural context. Thus, despite the many challenges faced in providing empirically meaningful data, the headspace sampling technique and methodology would enable multifaceted, multidisciplinary engagement.

\section{How Does it Work}

Headspace in the laboratory enables analysis of volatile species in samples that can be efficiently partitioned into the headspace gas volume (the space found above the sample matrix often lying in the base of a glass vial) from either a liquid or solid matrix. Analytes are separated into the headspace area as a result of establishing a unique equilibrium between solutes and the stationary phase.

The technique allows for the qualitative and/or quantitative analysis of small percentages of volatile organic compounds (VOCs) and sample sizes for detection and analysis that are infinitesimal; ranging from 0.1 to $1 \%$ of the compounds (Tipler 2014: 33), or sample material (depending on type of material, solid or liquid) ranging from 1 to $5 \mathrm{ml}$ or up to $10 \mathrm{ml}$. This means successful detection of volatile molecules 
deriving from odor in organic material at low levels, thus reducing the destructive nature of such testing on archaeological materials.

The method provides targeted and precise analysis of volatile organic compounds (VOCs) for separation, detection, and identification using GC-MS. Once the odorous VOCs are separated into the headspace from the stationary or sample phase, the analytes are sent through an inert carrier gas in the GC gas column into the MS. Generally, separation is conducted using an oven which heats the molecules within the glass vial containing the sample matrices to cause the transfer of the odor molecules from one phase to the other. The GC-MS process detects and identifies the analytes based on their mass and molecular fragmentation patterns. The analysis is presented as computer-generated data which, then, requires interpretation (Hamm et al. 2005: 1509-1510; Restek 2000; Tipler 2014: 3-5, 33).

There are several types of headspace sampling from dynamic, static, and solid-phase microextraction (SPME) or thermal desorption (TD) methods depending on the type of analytes and material samples being tested and the type of precision required in analysis (Restek 2008, 2018; Tipler 2014: 26-27; Vas and Vékey 2004). However, all techniques are dependent on creating equilibrium in vapor pressure to separate the analytes from the base solution.

\section{Static headspace}

Static headspace sampling allows for the concentration and assay of volatile organic compounds and provides a high degree of sensitivity. Using the static headspace sampling technique, the samples are put into quartz tubes and heated in a contained headspace vial. The vial is heated at a suitable temperature to separate the analytes from the rest of the sample matrix.

The headspace is placed at the front of the GC-MS, where the volatized and separated compounds are extracted. Injected into and swept onto the GC column via an inert carrier gas, the analytes proceed through the GC-MS process where each one is separated, identified, and represented graphically and in a tabulated format (Hamm et al. 2005: 1499-1514).

\section{Dynamic headspace sampling}

Dynamic headspace is a technique very similar to equilibrium, or static, headspace sampling but is intended to direct most, if not all, of the headspace vapor into the GC column. Dynamic headspace sampling can identify lower abundances of odor molecules which may be useful in some archaeological contexts. By using a two-needle approach to puncture the vial seal to introduce the carrier gas, it provides an outlet for the analytes to be carried through to the GC phase. Potentially, this offers greater precision, but detection at lower levels are the main benefit for archaeological purposes.

A typical dynamic headspace setup uses a stream of carrier gas to drive the headspace vapor into a suitable trap. A headspace trap system is where analytes go into trap desorption mode before being carried off into the GC process (Tipler 2014: 27). This system is also known as "headspace trap sampling" (see below). The "trap" normally comprises a series of adsorbent beds that will retain the analytes. Dynamic sampling has the advantage of being able to improve detection limits for analytes in samples by a factor of 100 or more (Restek 2000; Tipler 2014: 26). 


\section{Headspace trap sampling}

Headspace trap sampling (a form of dynamic headspace sampling) creates equilibrium to produce a stable headspace vapor. Headspace vapor is extracted, and the compounds effectively "trapped". The thermally desorbed analytes are carried through to the GC column and onto the MS (Restek 2018; Tipler 2014: 27).

\section{SPME}

Solid phase microextraction (SPME) is a technique that uses a solid (sorbent) or liquid (polymer) fiber coating with the extraction phase (Zhu et al. 2016). The preparation process for odor extraction has become popular, as it allows analysts to extract a concentrated and purified amount from the samples for analysis.

Additionally, in solid phase cases, the filament or SPME fiber can be placed within the vial and left for a period of time to collect the analytes that move into the headspace area. The quantity of analytes extracted by the fiber is proportionate to the concentration in the sample on reaching equilibrium and therefore presents a case for results having greater precision and accuracy (Augusto et al. 2013: 14-23; Vas and Vékey 2004). This technique can be used with a wide variety of matrices, but as with all sampling techniques, there is a great dependence on the substrates reaching equilibrium as discussed earlier.

\section{Thermal Desorption (TD)}

Thermal desorption has become part of headspace sampling technique, providing a more precise means of collecting and analyzing samples. It is a highly sensitive alternative and can be a more efficient way of extracting a selected concentration of target analytes. TD works for almost all volatile, and many semi-volatile compounds, and concentrations from ppm to ppt can be analyzed reliably.

The process of collection and desorption of analytes from solid or liquid sorbents uses heat and a flow of inert gas. Analytes are focused on a cold trap prior to entering the GC-MS process, resulting in higher responses and narrower more precise peak responses (Restek 2008: 1-4, 2018). However, unlike other headspace techniques, TD is not suitable for less volatile compounds, compounds that are either incompatible with standard gas chromatography, or those that require special care during GC analysis (e.g., on-column injection). On the other hand, TD is compatible with many sample matrices as with other headspace techniques including air, powders, fibers, films and granules, resins, pastes, and plastics (Curran et al. 2018: 7336-7340; Restek 2008: 3-4).

In summary, all headspace techniques operate by creating equilibrium in vapor pressure to separate the analytes from the base solution, separated analytes are detected, identified, and the results produced as a digital graphic representation. The method used will vary depending on the type of samples or VOCs that are being analyzed and future research would be required to delve deeper into the effectiveness of each of the variants on the headspace analysis technique. 


\section{Discussion}

On collection, samples already emitting a strong pungent odor prior to analysis, suggest the presence of volatile olfactory biomarkers. To attain accurate odorous readings from, for example, pungent mummy bindings, analysis would be expected to reveal evisceration and a human source of decomposition of the internal organs as indicative of the embalming treatment.

Headspace analysis would be expected to reveal both putrescene and cadaverine indicative of human decomposition. Results of odor signatures from nonvolatile human biomarkers (sterols and bile acids), could provide interesting results, as part of the body emanations and can be recorded, identified (as important information in the treatment of the body), and segregated from the evidence within the material record (reflecting on the preparation of the body) so that the evidence is not skewed. Such analysis can reveal the type of embalming agents applied to these internal organs as part of the anthropogenic preservation process, whereby the decomposed viscera is removed as a preservative measure during the mummification process (Buckley et al. 2007). This kind of data and subsequent evaluation from anthropogenic odor profiles could provide significant potential for ontological interpretation either as robust new evidence, a new interpretation, or to enhance and strengthen current theories around past mortuary and sociocultural practice.

Although the type of method employed depends on the type of samples or VOCs being analyzed, all techniques go through a similar process to separate analytes ready for detection and identification. Therefore, whether these strategies bring more precision to archaeological endeavors to finding smell in the laboratory or in the field is open to further exploration and debate.

\section{Considerations in the laboratory}

Using headspace in archaeology means that a large number of samples are not necessary. This reduces the destructive nature of scientific analysis on archaeological material, even though the nature of the test can be destructive (in removing a small sample). In addition, depending on the technique used, it is not always necessary to remove samples from the original material, but rather collect the odor analytes in situ. Thus, the nature of collecting odor does not necessarily have a destructive element. For example, using adsorption fibers (such as those used in SPME analysis), the fiber sits within the headspace area with the sample matrix in the vial or in situ (depending on the location of the material under analysis).

However, major concerns for this method are reproducibility and the role of the analyst. Due to the nature of calculations, this method is reliant on creating blank tests for comparisons with tests on sampled material, in constant temperatures, and exact volumes. When gases are spiked manually into the GC, the speed and technique in which an analyst does this plays a crucial role. Alternatively, using an automated sampler would seem more efficient and precise, but would also depend on how the analyst has set up the initial testing phase and program. Thus, consistency is key. 


\section{Challenges in the laboratory}

Challenges present themselves in maintaining equilibrium, temperature, and time in attempting to transfer the analytes from one phase into the headspace phase. Once the sample is placed inside an uncontaminated vial and sealed, volatile compounds from the sample will partition into the headspace until a state of equilibrium is reached. The rate at which volatile compounds partition out of the sample matrix and into the headspace (which can prove to be 15 minutes, an hour, or overnight).

Every compound has a thermodynamic energy presence in the headspace phase and in the liquid phase. These properties dictate how the molecules will distribute themselves (Restek 2000: 2-9; Tipler 2014: 4), thus attaining equilibrium is fundamental to the analytical results.

Time can be used to improve the transfer of volatile analytes from the sample into the headspace of the vial. Enough time must be built into the sample cycle in order to achieve a constant state of equilibrium. Some sample matrices require longer equilibration times due to physical characteristics like high viscosity.

Furthermore, adjusting the temperature of the sample can change the solubility of the analyte in the sample matrix and can be used to drive the equilibrium in favor of the gas phase. The more volatile compounds will tend to move into the gas phase (or headspace). The more volatile the compound, the more concentrated it will be in the headspace. Conversely, the less volatile (and more GC-unfriendly) components that represent the bulk of the sample will tend to remain in the liquid phase (Restek 2000: 9; Tipler 2014: 3, 14, 16). Additionally, incomplete or inefficient transfer of high molecular weight compounds or water vapor from sample matrices can produce adsorptive areas in the transfer line or injection port that can lead to split peaks, tailing peaks, or irreproducible responses or retention times. It may be necessary to use a higher transfer line temperature $\left(\sim 125^{\circ} \mathrm{C}-150^{\circ} \mathrm{C}\right)$ to minimize matrix problems and prevent water condensation from aqueous samples.

Further challenges include:

- Data corruption if there is a lack of precision in analysis time and resolution as two critical factors when developing a GC assay for ethanol. Analysis time for each sample should be as short as possible while still maintaining baseline resolution for all analytes (Restek 2000: 11).

- Temperature may also have an impact on the ease of collection of the analyte. The best technique in capturing the compounds can impact on the results presented (e.g., cold surfaces, solvent traps, and adsorbent materials), with the latter techniques being the best for longer periods of collection (Restek 2000, 2018; Tipler 2014: 3).

- Context and location of sample collection: whether in the field or in an archive environmental and physical context of the sample taken from are considerations particularly in understanding how the analysis of the odorant structure may be affected.

- Rate of degradation requires recording and considerations made around changes to a compound due to degradation: the original compound can "devolve" over time. The changes, for example, from a hydrocarbon to an acid can be a result of exposure and degradation over time; additionally if found in the soil, considerations must be paid to whether the odor compounds within the soil affect the odor VOCs within the material record - thus environmental odor testing also requires collection 
and analysis to understand its effects and to record and remove these compounds when searching for the original odor biomarkers within the material.

- Considerations of what biomarkers are being assessed: recognizing and interpreting what compounds may be suggested, a biomarker may suggest a chemical signature that can be associated with several substances that are potentially found in ancient as well as modern synthesized products; using a "record and remove" method to identify a potential (ancient) odorous chemical profile: that is, record all biomarker information and remove from the record those that are ghost peaks, part of the blank test, that are immediately identifiable as modern compounds so that only those that can be identified as being nestled within the context of the material sample which may indicate odorous chemical signatures, accounting then for the odor VOCs compacted within the fibers of a sample and how it may have evolved as it has become more and more exposed over time. Therefore, taking account of its historical exposure journey and its present exposure presence at the point of analysis becomes part of the challenge.

- Preparation of samples for headspace/GC-MS to maximize the concentration of the volatile sample components while minimizing unwanted contamination from other compounds in the sample matrix (for example, sample matrices such as biological samples, plastics, and cosmetics can contain high molecular weight, volatile material that can be transferred to the GC system and interfere with the results (Restek 2000: 5):

- High-concentration samples need to be prepared appropriately to obtain optimal chromatography. But high-concentration samples can produce ghost peaks in subsequent analyzes due to carryover of sample from previous injections, injecting standards, and samples in order from low to high concentrations to help minimize carryover.

- Sample carryover can be minimized by using higher transfer line and injection port temperatures, though some samples may need to be diluted and re-analyzed to obtain reliable results.

- Dealing with sample carryover or ghost peaks may require "baking out" the column at its maximum operating temperature and elevating the transfer line temperature in order to remove all of the residual sample. If high-concentration samples are anticipated in a sequence of samples, running a blank after the suspected samples will reduce carryover contamination of following ones (Restek 2000).

- Sample vials have to be selected to match the type and size of the sample being analyzed. Always pre-clean vials for sample preparation and storage to avoid as far as possible adsorption of contaminants which can produce unknown chromatographic peaks, or "ghost peaks." Running blanks is vital with any analysis for comparisons, but it can help to discard ghost peaks identified from the result of vial contamination (Restek 2000: 8). Therefore, handling blank or control matrices alongside sample matrices in the same way must become part of the analysis phase to ensure any vial or sample preparation problems are easily identified (Omar et al. 2016: 868, 873).

- Finally, it is necessary to be constantly aware of possible contamination factors in the compounds being analyzed and the potential for newly introduced contamination during laboratory testing which may impair the end results. 


\section{Considerations in the field}

Collecting samples in the field on site excavations as well as museum archives demand specific strategies. The combination of headspace analysis and known excavation techniques may provide stronger evidence for the importance of empirical data providing an added dimension to strengthen or create immutable foundations upon which to build archaeological narratives.

Samples can be collected from any environment, essentially any organic material culture is likely to have detectable odor VOCs initially from emissions during collection, but which can be more accurately determined through analysis. Although the emission during collection could be an indication of exposure to air and instant effects of degradation, the exudation would suggest the odor VOCs lay compacted within the material and are emitted on disturbance during excavation.

The type of sample collection strategy that can feasibly be undertaken to ensure that these compacted molecules are not too disturbed becomes a question for the field archaeologist. Thus, the consequences of using this technique could prove significant in the way we consider exploration in the field,

Different features and landscapes require different sampling techniques, as different types of organic material will demand different methods of odor collection. Essentially, what is required are containers that can be sealed and maintain inertia during active (used for short-term monitoring) or passive sampling (used for long-term monitoring). This could include reusable thermal desorption tubes, metal vacuum-sealed container, plastic (nalophan) bags (properly sealed) as viable containment units (Restek 2016).

There is also potential to use an auguring system (e.g., for a cesspit, or where a sample extract is buried deep within the soil of an excavation section). Such a method could ensure collection in situ and fast transference to a sealed container with minimal exposure to oxidization, an important consideration to ensure that the maximum number of odorants are collected in the sample.

\section{Methods of collection}

Collections happening at different stages must be considered within enclosed spaces such as for archival or museum environments as much as on-site collection, both have similar factors but differing effects on the results which must be taken into account. Exposure time can allow opportunity for molecular degradation or lighter volatile dissipating as time lapses from excavation process to collection and vacuum sealing processes, transference times as well as heat exposure (particularly in hot summer seasons) may cause further degradation issues, thus ice may be required to keep temperatures of the containment unit low enough to encourage molecular inertia. Therefore, speed and alacrity are important issues.

The following taxonomy is suggested in both Tables 1 and 2:

- Sampling,

- Features,

- Odorous finds,

- Sampling strategies. 


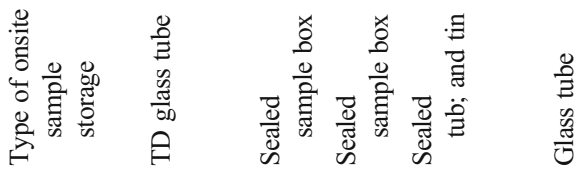

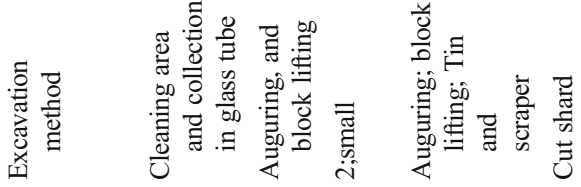

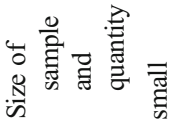

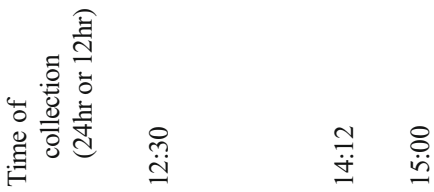

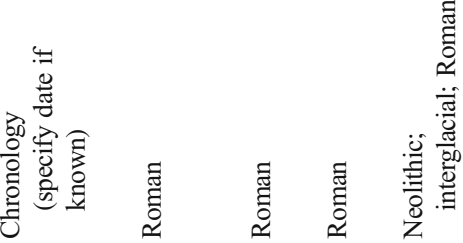

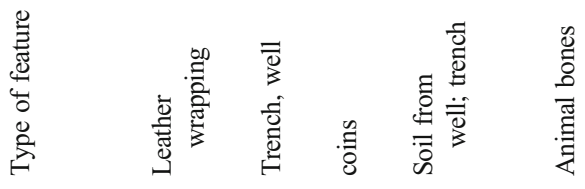

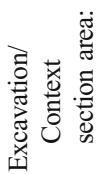

苛

离离

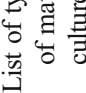

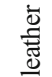

总

Бे

एँ

$\infty$ 편

00 忢

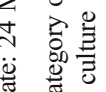

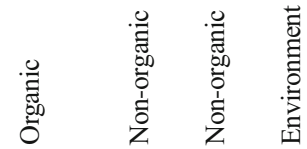


Table 2 Reference guide showing categories and recommended sample methods (Malik 2018)

Type of categories and possible sample methods for collecting material culture

\begin{tabular}{|c|c|c|c|c|c|c|}
\hline $\begin{array}{l}\text { Category } \\
\text { of material } \\
\text { culture }\end{array}$ & $\begin{array}{l}\text { List of types } \\
\text { of material } \\
\text { culture categories }\end{array}$ & $\begin{array}{l}\text { Type } \\
\text { of feature }\end{array}$ & $\begin{array}{l}\text { Chronology } \\
\text { (specify date } \\
\text { if known) }\end{array}$ & $\begin{array}{l}\text { Type } \\
\text { of site } \\
\text { (open or } \\
\text { closed) }\end{array}$ & $\begin{array}{l}\text { Type of } \\
\text { excavation } \\
\text { and } \\
\text { collection } \\
\text { method }\end{array}$ & $\begin{array}{l}\text { Type of } \\
\text { sample } \\
\text { storage }\end{array}$ \\
\hline Organic & $\begin{array}{l}\text { linen, cotton, silk, } \\
\text { leather, viscera, } \\
\text { faecal, sanguine, } \\
\text { wood, oil, } \\
\text { residual unguent, } \\
\text { sedimentary, } \\
\text { trapped air, plant }\end{array}$ & $\begin{array}{r}\text { Mummy } \\
\text { wrap- } \\
\text { pings }\end{array}$ & $\begin{array}{l}1^{\text {st }} \\
\text { millennium } \\
\text { BCE }\end{array}$ & $\begin{array}{l}\text { cave } \\
\text { burial } \\
\text { (enclos- } \\
\text { ed) }\end{array}$ & $\begin{array}{c}\text { Clean and } \\
\text { collect }\end{array}$ & $\begin{array}{l}\text { TD glass } \\
\text { tube; } \\
\text { sealed tins, } \\
\text { sample } \\
\text { tubs; ice } \\
\text { box }\end{array}$ \\
\hline Non-organic & $\begin{array}{l}\text { stone, glass, water, } \\
\text { metal, ceramic } \\
\text { clay }\end{array}$ & $\begin{array}{l}\text { Trench, } \\
\text { rubbish } \\
\text { pit, } \\
\text { well, } \\
\text { cesspit- } \\
\text { s, } \\
\text { rubbish } \\
\text { pits, } \\
\text { Burnt } \\
\text { pits }\end{array}$ & $\begin{array}{l}\text { Roman } \\
\text { Medieval } \\
\text { Prehistory, } \\
\text { Modern }\end{array}$ & $\begin{array}{l}\text { Open } \\
\text { excava- } \\
\text { tion }\end{array}$ & $\begin{array}{l}\text { augur, block } \\
\text { lift, deep } \\
\text { push } \\
\text { probe, tin } \\
\text { installed in } \\
\text { situ }\end{array}$ & $\begin{array}{l}\text { Sample tin or } \\
\text { tub Burnt } \\
\text { soil: glass } \\
\text { tubes; TD; } \\
\text { sample tins } \\
\text { Storage in } \\
\text { ice box }\end{array}$ \\
\hline Environment & Soil, water, air & $\begin{array}{l}\text { Air, soil } \\
\text { be- } \\
\text { tween } \\
\text { walls; } \\
\text { soil } \\
\text { from } \\
\text { burial } \\
\text { area }\end{array}$ & $\begin{array}{r}\text { Palaealithic } \\
\text { (possibly } \\
\text { 400kya) }\end{array}$ & $\begin{array}{l}\text { Cave } \\
\text { burial }\end{array}$ & $\begin{array}{l}\text { augur, block } \\
\text { lift, deep } \\
\text { push } \\
\text { probe, tin } \\
\text { installed in } \\
\text { situ; Air: } \\
\text { Diffusion } \\
\text { tube }\end{array}$ & $\begin{array}{l}\text { Storage in } \\
\text { tins: glass } \\
\text { tubes } \\
\text { storage: ice } \\
\text { box }\end{array}$ \\
\hline $\begin{array}{l}\text { Decayed } \\
\text { organics }\end{array}$ & $\begin{array}{l}\text { viscera, bone, } \\
\text { bacteria, fungi, } \\
\text { plant }\end{array}$ & $\begin{array}{l}\text { Blood, } \\
\text { bone } \\
\text { marro- } \\
\text { w, plant }\end{array}$ & $\begin{array}{l}\text { Roman } \\
\text { Medieval } \\
\text { Prehistory }\end{array}$ & & $\begin{array}{c}\text { Clean and } \\
\text { collect }\end{array}$ & $\begin{array}{l}\text { Glass tubes } \\
\text { store in ice } \\
\text { box }\end{array}$ \\
\hline
\end{tabular}

Table 1 presents a possible odor sampling recording system, using a recent excavation at the Roman fort and Vicus site in Malton, England, as an example. However, it must be noted that the environmental form found in most on site manuals can also be used by simply adding two columns for odor sampling (Wessex Archaeology fieldwork recording manual 2010: 34). Initial sampling in the field may require a specialist, and specialist analysis is definitely necessary in the laboratory. It is possible for appropriately trained archaeologists to collect samples in the field.

Table 2 shows an initial reference guide indicating the kind of strategy required for each category and feature being sampled, for use by archaeologists in the field. The list of applications could be inexhaustive as many methods or strategies would be dependent on the sample types required for collecting odor compounds and the environment within which they reside. 
A further reference guide (not shown here) is necessary for results from laboratory analysis indicating materials, recording compounds, and charting the changes to the compounds due to degradation over time (i.e., how a hydrocarbon may turn into an acid compound over time). This will help future research by having access to recognizing specific compound changes and "devolutions" from the original through to the degraded and changed form.

Several sampling strategies already employed in fieldwork can be used for odor collection. For example, techniques for sedimentary sampling can be considered if gastight containers are used (Kibblewhite et al. 2015: 249-263). A sealed Kubiena tin, a plastic finds bag, a glass tube or vial, an adsorbent "trap" (tenax) tube, or a nalophan bag may all be used. As well as the type of container used for collection, further considerations also need to be paid to the speed of transferal, meaning the rate of exposure to air, and the conditions and pungency, the location of the sample, and the type of organic material being sampled.

In addition, the method used may depend on the site as well as material factors as mentioned above. Reviewing the site and deciding on what environmental impacts it has is an important aspect for the archaeologist to consider in order to employ the most effective method of collection. Clearly, decisions about methods and strategies will also be informed by the research agendas and questions for an excavation before discussions on logistics and machinations necessary for odor sampling take place.

\section{Challenges in the field}

There are several factors to consider in collecting odor samples in the field, apart from the containers used for sampling. Factors include the impact on the landscape, the environmental impact of open and closed excavation sites, the time taken to collect samples as well as exposure to the environment before containment, recording the samples collected, and generally the type of strategies that must be consequently employed in the field. For example, environmental exposure time in summer may require avoidance tactics (such as ice boxes) to reduce molecular degradation and maintain molecular inertia.

It should be noted that underwater sites are not discussed here but methods for sampling odor molecules in situ would need consideration within the palette of what is achievable using current underwater sampling techniques. There are many factors that contribute to the preservation of archaeological objects that may also apply to terrestrial material culture (Historic England 2016a: 5- 8, b: 2-24) including:

- Exposure time,

- Little or no oxygen,

- Little or no moisture,

- High or low turbidity.

Because odorants potentially have a more unstable or unpredictable character, the impact on degradation of sample material has to be considered by archaeologists in the field as much as by analysts in the laboratory. Thus, there are challenges that should be considered prior to sampling, such as (Cronyn 1990; Historic England 2016a: 10-15, b: 2-24): 
a. Molecular retention - in that sample loss may occur due to volatility of molecules, whereby the chemical structure does not remain intact and uncompromised at a molecular level, but rather becomes diluted and dispersed causing difficulties when attempting to analyze.

b. Type of sampling equipment that will maintain inert molecules or create an inert environment for reducing vibration or volatility - to avoid partial or complete degradation or decomposition material due to exposure to the surrounding environment, oxidization, or moisture (hydrolysis).

c. Sealed containment is essential to trap the odor molecules and to maintain their inertia prior to reaching the laboratory for analysis. As long as containers are of an inert material, such as metal, plastic or glass - sealed containers can be used to handle sedimentary organic materials.

d. Sizes of the box and samples in an attempt to minimize exposure to air during containment - the sample should fit the box so that no more air can be trapped within alongside the volatile molecules already present in the sample.

e. Type of sample required (i.e., whether or not part of soil inclusion is necessary) as well as exposure to air which can have an effect of concentrating or degrading the odor particle preservation (in some cases there is a risk of altering the smell entirely).

Additionally, physical damage can be caused by abrasion, stress, or organisms in a burial environment. Chemical damage on archaeological sites can be caused by water, oxygen, organisms, pH, ions, and light (Cronyn 1990; Historic England 2016b: 2, 17 20, 22-24):

- Water $\left(\mathrm{H}_{2} \mathrm{O}\right)$ acts as a catalyst for many reactions including hydrolysis and electrochemical reactions and is a key component in many living organisms affecting corrosion of objects and changes in odor emanation. Moisture in the air may affect preservation or deterioration fand affect the solubility of materials and thus odor differential from the original scent.

- Oxidization causes degradation, hence exposure (and rate of exposure) to the atmosphere is a key consideration in sampling odorants.

- Some micro-organism can cause chemical damage in their bacterial or enzymatic secretions.

- The $p H$ of the environment can encourage or limit biogrowth and cause materials to degrade at higher or lower $\mathrm{pH}$ levels.

- Ions present in the soil or water surrounding an object can be damaging. On waterlogged sites, ions (such as chlorides) can cause corrosive activity that has an effect on olfactory emanations (Buckley and Evershed 2001; Buckley et al. 2007; Restek 2016: 1-28; Tipler 2014).

- Light absorbed by organic objects can cause or promote an oxidizing reaction having an effect on the odor emissions.

These challenges can influence the final odor emanations and potentially compromise the samples. Nevertheless, it is the presence of odor biomolecules as unique "chemical fingerprints" (Buckley et al. 2007: 39) still remaining in the archaeological material for which the analyst will be looking. 
In considering sample collection (and testing), corruption and degradation from excavation or laboratory work can lead to some impact on odorant survivability. Where pungency is "visible," we can surmise these are made up of heavier volatile molecules - although pungency may also be an effect of exposure to air.

Although any organic material with an associated odor is a candidate for olfactory sample collection, its quality of preservation may be an issue. The better odor preservation in materials would suggest that these remains are dominated by the more pungent odor molecules. These heavier molecules may indicate the presence of the original compounds remaining in situ, but it is not the full story. Preservation bias must be taken into account for any analysis and ultimate interpretation of the data.

This bias can be levelled at all uses of scientific analysis in archaeology and to some extent it is unavoidable. But with this awareness comes responsibility to ensure greater caution, accuracy, and precision in testing, and subsequently in the interpretations and metanarratives created from such empirical evidence.

Although clearly it is important to be mindful of biases, sampling and subsequent analysis can still be seen as noteworthy qualitative and quantitative evidence. The accumulated material provides a picture that may not entirely reflect the original by the time the collected samples have been analyzed. Nonetheless, the data can still provide meaningful and significant insights. Therefore, analysis of the volatile odor compounds requires diagnostic methods and protocols to evaluate a sample's composition and enable metanarratives to bring greater depth and credence (Omar et al. 2016: 867-873). The information still provides building blocks for future work, as long as we are aware of preservation bias in the record.

To reiterate, in the field, careful consideration must be paid when reviewing the site and deciding what environmental impacts it has on the specific kind of odor we are aiming to collect. This will depend as much on the research questions as it will on the inclusion in the early design phase of a project. Therefore, the most efficient methods, the types of sample collection required, and the type of features that may suggest potential odor associations must be considered as a standard part of any research question in the future.

Furthermore, using these methods and strategies may suggest that archaeologists need to have a level of knowledge about their site landscapes and to have an awareness of the many methods and techniques that could be used or manipulated to access odor particles. This can be simply achieved by training archaeologists to use current sampling techniques to collect odor particles in the field in the same manner as collecting soil or material remains.

\section{Conclusion: Finding "Ancient" Smells}

Odor is integral and innate to human evolution and cognition. Smell, as a communicative process, has impact on cognitive adaptation. Collectively and individually, olfactory information is constantly and actively coding and encoding information feeding into memory, interpretation, adaptation, and ultimately, lived experience.

Headspace analysis, like other biogenetic analyses examining ancient molecular structures (Brettell et al. 2017: 348; Nicholls 2005: 192-96; Pevsner 2015: 1160), can be used in any period of time, across any type of organic preservation, in the field and in heritage institutions and archives. The nature of heavy volatile molecules means that 
they can be sampled and analyzed wherever they are retained within the organic material. The use of headspace sampling brings us closer to the smell of the past in the present (Cano 1996: 162-167).

Indeed, Buckley et al. (2004) employed the headspace sampling technique to analyse prehistoric origins of Egyptian mummification in late Neolithic burials (Jones et al. 2014: 1-13). This study demonstrates the great potential headspace sampling offers to access "ancient" odor in archaeology.

As previously mentioned, Jones et al.'s (2014) analysis of prehistoric funerary wrappings using headspace sampling with GC-MS, identified a pine resin, an aromatic plant extract, a plant gum/sugar, a natural petroleum source, and a plant oil/animal fat in funerary wrappings, which included the presence of antibacterial properties. Although not directly making assumptions centered around odor, the analysis indicated the use of aromatic ingredients.

The similarities in the recipes and embalming agents utilized at the height of body preservation in ancient Egypt strongly indicated that resin-impregnated textiles and the localized soft-tissue preservation are the true antecedents of Egyptian mummification practiced in some form for 5,000 years (Jones et al. 2014: 1, 2-13). This research could now be progressed using the information from headspace analysis to identify the aroma molecules present and to suggest the kind of odor profile that would have emanated at the time of wrapping a body. It may bring insight into the symbolic significance of the association with smell and mortuary practices. Thus, archaeological knowledge is further extended into whether, how, and why those substances were given existential importance within specific past sociocultural constructs.
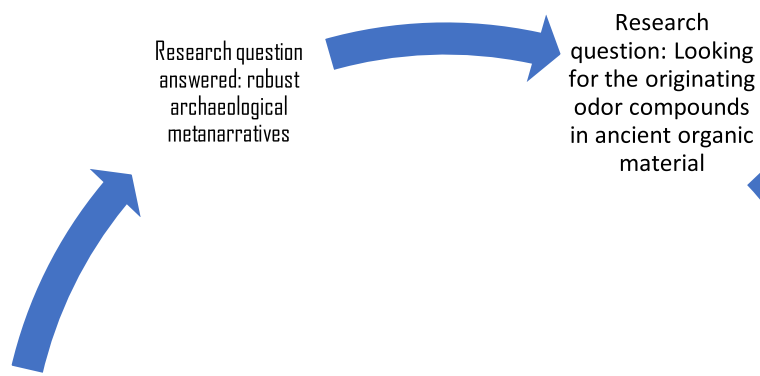
material

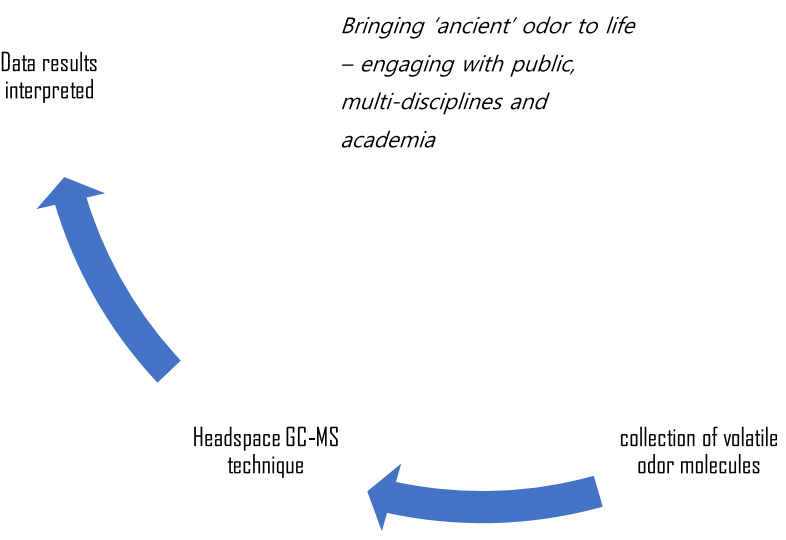

Fig. 7 Process for using odor as a primary source 
These studies demonstrate how archaeologists can bridge the gap by combining scientific data with conceptual interpretations to consider another dimension for understanding past cultures. Headspace analysis can serve archaeologists to better interpret how smell interconnects both at a conscious and subconscious level for human comprehension, manipulation, maneuverability, and adaption to environments that are essential, existential, spatial, temporal, and interactive.

Moreover, the headspace sampling technique demonstrates that smell in field archaeology is no longer intangible, ethereal, invisible, or incorporeal. However, field archaeology requires a further evolution to allow odorous empirical evidence, sample collection, and conceptualization to enter its sphere in order to dynamically and multidimensionally support broader themes in religion and ritual, gender, leadership, trade, and communications.

Death and burial and the treatment of the body is clearly the most apparent theme with which to begin to illustrate how odorous data can answer some fundamental ontological questions in the metanarrative around the associative nature of odor and past mortuary practices (Fig. 7).

To summarize, odor is a morphological or micromorphological record (Huisman and Majid 2018; Usai et al. 2010). The examination of smell presents clues into cognitive adaptations of past cultural constructs which might otherwise escape our current, spatio-temporally distanced comprehensions. Headspace sampling can bring tangible evidence of odor to extend our understanding of sociocultural development from its earliest manifestations of human existence into the present day. Instead of discussing empirical and ephemeral arguments separately, we can now combine them to consider mesa data and meta narratives together to fortify, refine, or redefine understandings of past cultures. In other words, we can find and engage with smell in the past as primary source evidence.

\section{Compliance with ethical standards}

Conflict of Interest The author declares that they have no conflict of interest

Open Access This article is licensed under a Creative Commons Attribution 4.0 International License, which permits use, sharing, adaptation, distribution and reproduction in any medium or format, as long as you give appropriate credit to the original author(s) and the source, provide a link to the Creative Commons licence, and indicate if changes were made. The images or other third party material in this article are included in the article's Creative Commons licence, unless indicated otherwise in a credit line to the material. If material is not included in the article's Creative Commons licence and your intended use is not permitted by statutory regulation or exceeds the permitted use, you will need to obtain permission directly from the copyright holder. To view a copy of this licence, visit http://creativecommons.org/licenses/by/4.0/.

\section{References}

Augusto, F., Hantao, L. W., Mogollón, N.G.S., and Braga, S. (2013). New materials and trends in sorbents for solid-phase extraction. TrAC Trends in Analytical Chemistry 43: 14-23.

Bartosiewicz, L. (2003). There's something rotten in the state. . . : bad smells in antiquity. European Journal of Archaeology 6: 175-195.

Bembibre, C. and Strlič, M. (2017). Smell of heritage: a framework for the identification, analysis and archival of historic odours. Heritage Science 52: 1-11. 
Brettell, R. C. and Heron, C. (2016). The fragrant dead. Current Archaeology 312.

Brettell, R. C., Stern, B., Reifarth, N., and Heron, C. (2014). The "semblance of immortality"? resinous materials and mortuary rites in Roman Britain. Archaeometry 56(3): 351-526.

Brettell, R., Martin, W., Atherton-Woolham, S., Stern, B., and McKnight, L. (2017). Organic residue analysis of Egyptian votive mummies and their research potential. Studies in Conservation 62(2): 1-121.

Buckley, S. and Evershed, R. (2001). Organic chemistry of embalming agents in Pharaonic and GraecoRoman mummies. Nature 413: 837-841.

Buckley, S., Fletcher, J., Al-Thour, K., Basalama, M., and Brothwell, D. R. (2007). A preliminary study on the materials employed in ancient Yemeni mummification and burial practices (summary). Proceedings of the Seminar for Arabian Studies 37: 37-41.

Buckley, S., Clark, K. A, and Evershed, R. (2004). Complex organic chemical balms of pharaonic animal mummies. Nature 341: 294-298.

Bushdid, C., Magnasco, M. O., Vosshall, L. B., and Keller, A. (2014). Humans can discriminate more than 1 trillion olfactory stimuli. Science 343: 1370-1372.

Cano, R. J. (1996). Analysing ancient DNA. Elsevier Science Ltd. PII: SOlSO-9327 96: 162-167.

Classen, C., Howes, D., and Synnott, A. (1994). Aroma: The Cultural History of Smell. Routledge, London.

Classen, C. (1993). Worlds of Senses: Exploring the Senses in History and across Cultures. Routledge, London.

Classen, C. and Howes, D. (2014). Ways of Sensing: Understanding the Senses in Society. Routledge, London.

Cronyn, J. M. (1990). The Elements of Archaeological Conservation. Routledge, London.

Curran, K., Underhill, M., Grau-BovØ, J., Fearn, T., Gibson, L. T., Strlic, M. (2018). Artefacts by their smell. Angew. Chemistry. International 57: $7336-7340$.

Day, J. (2013). Introduction: making senses of the past. In Day, J. (ed.). Making Senses of the Past: Toward a Sensory Archaeology, Southern Illinois University Press, Carbondale, pp. 1-31.

d'Errico, F., Henshilwood, C., Lawson, G., Vanhaeren, M., Tillier, A.-M., Soressi, M., Bresson, F., Maureille, B., Nowell, A., Lakarra, J., Backwell, L., and Julien, M. (2003). Archaeological evidence for the emergence of language, symbolism, and music: an alternative multidisciplinary perspective. Journal of World of Prehistory 17(1): 1-70.

Dong, D., He, G., Zhang, S., and Zhang, Z. (2009) Evolution of olfactory receptor genes in primates dominated by birth-and-death process genome. Biological Evolution 1: 258-264.

Engen, T. (1982). The Perception of Odours. Academic Press, London.

Franklin, S. and Ferkin, M. (2006) An ontology for comparative cognition: a functional approach. Comparative Cognition and Behaviour Reviews 1: 36-52.

Halbwachs, M. (1950). Collective Memory. Coser, L. A. (trans.). Chicago University Press, Chicago.

Hamilakis, Y. (2010). Re-collecting the fragments: archaeology as mnemonic practice. In Lillios, K. T. and Tsamis, V. (eds.). Material Mnemonics: Everyday Memory in Prehistoric Europe. Oxbow, Oxford.

Hamilakis, Y. (2002). The past as oral history: towards an archaeology of the sense. In Hamilakis, Y., Pluciennik, M., and Tarlow, S. (eds.), Thinking Through the Body: Archaeologies of Corporeality. Plenum, New York.

Hamm, S., Bleton, J., Connan, J., and Tchapla, A. (2005). A chemical investigation by headspace SPME and GC-MS pf volatile and semi-volatile terpenes in various olibanum samples. Phytochemistry 66: 14991514.

Hardy, K. (2018). Plant use in the lower and middle Palaeolithic: food, medicine and raw materials. Quaternary Science Reviews 191: 393-405.

Hardy, K., Buckley, S., and Huffman, M. (2013). Neanderthal self-medication in context. Antiquity 87: 873878.

Hardy, K., Buckley, S., Collins, M. J., Estalrrich, A., Brothwell, D., Copeland, L., García-Tabernero, A., García-Vargas, S., de la Rasilla, M., Lalueza-Fox, C., Huguet, R., Bastir, M., Santamaría, D., Madella, M., Wilson, J., Fernández Cortés, Á., and Rosas, A. (2012). Neanderthal medics? evidence for food, cooking, and medicinal plants entrapped in dental calculus. Naturwissenschaften 99: 617-626.

Harvey, S. A. (2006). Scenting Salvation: Ancient Christianity and the Olfactory Imagination. University of California Press, Berkeley.

Heyes, C. (2012). New thinking: the evolution of human cognition. Philosophical Transactions of the Royal Society of London B 367: 2091-2096.

Historic England. (2016a). Preserving Archaeological Remains: Decision-Taking for Sites under Development. Historic England, London.

Historic England. (2016b). Preserving Archaeological Remains: Appendix 2 - Preservation Assessment Techniques. Historic England, London. 
Hodder, I. (2016). Studies in Human-Thing Entanglement, CC Publishing, London.

Hodgson, D. (2008) The visual dynamics of upper Palaeolithic cave art. Cambridge Archaeological Journal 18: $341-353$.

Hoehn, R. D., Nichols, D. E., Neven, H., and Kais, S. (2018). Status of the vibrational theory of olfaction. Frontiers in Physics 6(25): 1-16.

Hoover, K. C., Gokcumen, O., Qureshy, Z., Bruguera, E., Savangsuksa, A., Cobb, M., and Matsunami, H. (2015). Global survey of variation in a human olfactory receptor gene reveals signatures of non-neutral evolution. Chemical Senses 40: 481-488.

Huisman, J. and Majid, A. (2018). Psycholinguistic variables matter in odor naming. Memory and Cognition 46: $577-588$.

Jones, A. (2007). Memory and Material Culture. Cambridge University Press, Cambridge.

Jones, J., Higham, T., Oldfield, R., O’Connor, T., and Buckley, S. A. (2014). Evidence for prehistoric origins of Egyptian mummification in late Neolithic burials. PLOS ONE 9(8): 1-14.

Kibblewhite, M., Tóth, G., and Hermann, T. (2015). Predicting the preservation of cultural artefacts and buried materials in soil. Science of the Total Environment 529: 249-263.

Malafouris, L. (2017). Material engagement and the embodied mind. In Wynn, T. and Coolidge, F. (eds.), Cognitive Models in Palaeolithic Archaeology. Oxford University Press, New York, pp. 69-87.

Malafouris, L. (2004). The cognitive basis of material engagement: where brain, body and culture conflate. In DeMarrais, E., Gosden, C., and Renfrew, C. (eds.), Rethinking Materiality: The Engagement of Mind with the Material World. McDonald Institute, Cambridge.

Miller, M. J., Albarracin-Jordan, J., Moore, C., and Capriles, J. M. (2019). Chemical evidence for the use of multiple psychotropic plants in a 1,000-year-old ritual bundle from South America. PNAS 116(23): 11207-11212.

Morley, I. (2002). Evolution of the physiological and neurological capacities for music. Cambridge Archaeological Journal 12(2): 195-216.

Morley, I. (2006). The Evolutionary Origins and Archaeology of Music. Doctoral dissertation, University of Cambridge, Cambridge.

Nicholls, H. (2005). DNA Comes of Age. LOS Biology, 3: 192-196.

Niimura, Y., Matsui, A., and Touhara, K. (2014). Extreme expansion of the olfactory receptor gene repertoire in African elephants and evolutionary dynamics of orthologous gene groups in 13 placental mammals. Genome Research Online Edition pp. 1-14.

Niimura, Y. and Nei, M. (2003). Evolution of olfactory receptor genes in the human genome. PNAS 100(21): $12235-12240$.

Nimura, Y. and Nei, M. (2005). Evolutionary dynamics of olfactory receptor genes in fishes and tetrapods. PNAS 102(17): 6039-6044.

Niimura, Y. (2009). Evolutionary dynamics of olfactory receptor genes in chordates: Interaction between environments and genomic contents. Human Genomics 4(2): 107-118.

Omar, J., Olivares, M., Alonso, I., Vallejo, A., Aizpurua-Olaizola, O., and Etxebarria, N. (2016). Quantitative analysis of bioactive compounds from aromatic plants by means of dynamic headspace extraction and multiple headspace extraction-gas chromatography-mass spectrometry. Journal of Food Science 81(4): 867-873.

Pettitt, P., Castillejo, A. M., Arias, P., Peredo, P. O., and Harrison, R. (2014). New views on old hands: the context of stencils in El Castillo and La Garma caves (Cantabria, Spain). Antiquity 88: 47-63.

Pevsner, J. (2015). Bioinformatics and Functional Genomics. Wiley-Blackwell, London.

Reinarz, J. (2014). Past Scents: Historical Perspectives on Smell. University of Illinois Press, Urbana.

Restek (2000). A Technical Guide for Static Headspace Analysis, Using GC. Bellefonte, PA. https://restek. com/pdfs/59895B.pdf.

Restek (2008). Thermal desorption tubes: versatile air sampling for a wide range of applications. EVFL1065: 1-4. Bellefonte, PA. https://restek.com.

Restek (2016). Thermal desorption: a practical applications guide: i. environmental air monitoring and occupational health and safety, EVTG1034: 1-28. Bellefonte, PA. https://restek.com.

Restek (2018). Thermal desorption: a practical applications guide: iv. food, flavour, fragrance and odour profiling. FFTG1037.pdf: 1-28. Bellefonte, PA. https://restek.com.

Rifkin, R. F. (2009). Engraved art and acoustic resonance: exploring ritual and sound in north-western South Africa. Antiquity 83: 585 - 601 .

Saul, H., Madella, M., Fischer, A., Glykou, A., Hartz, S., and Craig, O. E. (2013). Phytoliths in pottery reveal the use of spice in European prehistoric cuisine. PLOS ONE 8(8): 1-5.

Skeates, R. (2010). An Archaeology of the Senses: Prehistoric Malta. Oxford University Press, Oxford. 
Tipler, A. (2014). An Introduction to Headspace Sampling: Fundamentals and Theory. PerkinElmer, Waltham, MA.

Thomas, J. (2013). Scents and sensibilities: the phenomenology of late Neolithic Iberian slate plaque production. In Day, J. (ed.), Making Senses of the Past. Southern Illinois University Press, Carbondale.

Tringham, R. (2013). A Sense of Touch - the Full-Body Experience - in the Past and Present of Çatalhöyük, Turkey. In Day, J. (ed.), Making Senses of the Past. Southern Illinois University Press, Carbondale.

Turin, L. (1996). A spectroscopic mechanism for primary olfactory reception. Chemical Senses 21(6): 773-91.

Usai, M., Brothwell, D., Buckley, S., Al-Thour, K., and Canti, M. (2010). Micromorphology of two prehistoric ritual burials from Yemen, and considerations on methodological aspects of sampling the burial matrix - work in progress. Geophysical Research Abstracts 12: 1-2.

Vas, G. and Vékey, K. (2004). Solid-phase microextraction: a powerful sample preparation tool prior to mass spectrometric analysis. Journal of Mass Spectrometry 39: 233-254.

Wessex Archaeology (2010). Wessex Archaeology Fieldwork Recording Manual. Wessex Archaeology, Salisbury.

Woolgar, C. (2006). The Senses in Late Medieval England. Yale University Press, New Haven, CT.

Zhu, H., Zhu, J., Wang, L., and Li, Z. (2016). Development of a SPME-GC-MS method for the determination of volatile compounds in Shanxi aged vinegar and its analytical characterisation by aroma wheel. Journal of Food Science Technology 53(1): 171-183.

Publisher's Note Springer Nature remains neutral with regard to jurisdictional claims in published maps and institutional affiliations. 